\title{
Stable Calcium Isotopes: a novel biomarker of bone mineralization in children with chronic kidney disease
}

\author{
R. SHROFF ${ }^{1}$, A. KOLEVICA ${ }^{2}$, A. HEUSER ${ }^{2}$, A. \\ LALAYIANNIS $^{1}$, D.-C. FISCHER ${ }^{3}$ AND A. EISENHAUER ${ }^{2 *}$ \\ ${ }^{1}$ Great Ormond Street Hospital for Children and UCL \\ Institute for Child Health, London, UK \\ ${ }^{2}$ GEOMAR, Kiel, Germany \\ ${ }^{3}$ Rostock Univ. Medical Hospital, Rostock, Germany
}

In chronic kidney disease (CKD) dysregulated calcium (Ca) homeostasis is associated with reduced bone mineral density (BMD) and vascular calcification. However, radiological measures and biomarkers do not allow accurate evaluation of BMD.

We measured $\mathrm{Ca}$ isotope ratios $\left(\delta^{44 / 42} \mathrm{Ca}\right)$ by MC-ICP-MS in blood and urine. Bone $\mathrm{Ca}$ gain and loss is calculated using a box model based on $\mathrm{Ca}$ kinetics. $\mathrm{Ca}$ absorption from bones increases $\delta^{44 / 42} \mathrm{CaBlood}$ and $\delta^{44 / 42}$ Caurine, resorption decreases these fractions.

104 children in CKD4-5 and on dialysis (CKD4-5D), 40 controls and 100 adults underwent $\mathrm{Ca}$ isotope measurement, bone biomarkers, dual energy $\mathrm{x}$-ray absorptiometry (DXA) and tibial peripheral quantitative CT scan (pQCT).

In healthy children $\delta^{44 / 42} \mathrm{CaBlood}$ and $\delta^{44 / 42} \mathrm{CaUrine}$ were higher than in adults $(\mathrm{p}<0.0001)$, reflecting Ca uptake during bone formation. Since urinary $\mathrm{Ca}$ excretion is impaired in CKD, $\delta^{44 / 42}$ CaBlood was higher and $\delta^{44 / 42}$ Caurine lower in children with CKD4-5D compared to controls $(p<0.001$ for both).

In CKD2-5D $\delta^{44 / 42}$ CaBlood positively correlated with cholecalciferol $(p=0.01)$ and alfacalcidol $(p=0.002)$ doses, implying increased bone $\mathrm{Ca}$ uptake when $\mathrm{Ca}$ bioavailability is increased. $\delta^{44 / 42} \mathrm{Ca}$ Blood positively correlated with biomarkers of bone formation (alkaline phosphatase, $p=0.05$ ) and negatively with bone resorption markers (PTH, p=0.013, TRAP5b, $\mathrm{p}<0.001, \mathrm{CTX}, \mathrm{p}=0.006) . \quad \delta^{44 / 42}$ CaBlood positively correlated with tibial cortical BMD-Z-score $(\mathrm{p}=0.006$, $\left.\mathrm{R}^{2}=0.39\right)$, and DXA hip BMD-Z-score $(\mathrm{p}=0.02)$. On multivariable linear regression analysis significant and independent predictors of tibial cortical BMD-Z-score were $\delta^{44 / 42}$ CaBlood $(\beta=0.68, p=0.006)$ and PTH $(\beta=0.39, p=0.04)$, together predicting $67 \%$ of the variability in BMD.

$\mathrm{Ca}$ isotope ratios provide a novel, non-invasive method of assessing bone mineralization. Further studies are in progress to define optimal levels of $\delta^{44 / 42} \mathrm{Ca}$ Blood that can guide safe and effective treatment to prevent Ca deficiency or overload. 